\title{
Fabrication of Novel Chitosan-Hydroxyapatite Nanostructured Thin Films for Biomedical Applications
}

\author{
Carmen Steluta Ciobanu ${ }^{1}$, Simona Liliana Iconaru ${ }^{1}{ }^{\mathbb{O}}$, Daniela Predoi ${ }^{1}$, Roxana-Doina Trușcă ${ }^{2}$, \\ Alina Mihaela Prodan ${ }^{3,4}$, Andreea Groza ${ }^{5}$, Mariana Carmen Chifiriuc ${ }^{6,7,8}$ (D) and Mircea Beuran ${ }^{3,4, *}$
}

check for updates

Citation: Ciobanu, C.S.; Iconaru, S.L.; Predoi, D.; Trușcă, R.-D.; Prodan, A.M.; Groza, A.; Chifiriuc, M.C.; Beuran, M. Fabrication of Novel Chitosan-Hydroxyapatite Nanostructured Thin Films for Biomedical Applications. Coatings 2021, 11, 1561. https://doi.org/ 10.3390/coatings11121561

Academic Editors: Alexandra Muñoz-Bonilla and Huirong Le

Received: 31 August 2021

Accepted: 17 December 2021

Published: 19 December 2021

Publisher's Note: MDPI stays neutral with regard to jurisdictional claims in published maps and institutional affiliations.

Copyright: (c) 2021 by the authors. Licensee MDPI, Basel, Switzerland. This article is an open access article distributed under the terms and conditions of the Creative Commons Attribution (CC BY) license (https:/ / creativecommons.org/licenses/by/ $4.0 /)$.
1 National Institute of Materials Physics, Atomistilor Street, No. 405A, P.O. Box MG 07, 077125 Magurele, Romania; ciobanucs@gmail.com (C.S.C.); simonaiconaru@gmail.com (S.L.I.); dpredoi@gmail.com (D.P.)

2 National Centre for Micro and Nanomaterials and National Centre for Food Safety, Faculty of Applied Chemistry and Materials Science, University POLITEHNICA of Bucharest, Splaiul Independentei 313, 060042 Bucharest, Romania; truscaroxana@yahoo.com

3 Emergency Hospital Floreasca Bucharest, 8 Calea Floresca, Sector 1, 014461 Bucharest, Romania; prodan1084@gmail.com

4 Department of Surgery, Carol Davila University of Medicine and Pharmacy, 8 Eroii Sanitari, Sector 5, 050474 Bucharest, Romania

5 National Institute for Laser, Plasma and Radiation Physics, 409 Atomistilor Street, P.O. Box MG 36, 077125 Magurele, Romania; andreea.groza@inflpr.ro

6 Life, Environmental and Earth Sciences Division, Research Institute of the University of Bucharest (ICUB), University of Bucharest, 060023 Bucharest, Romania; carmen.chifiriuc@gmail.com

7 Academy of Romanian Scientists, 54 Spl. Independentei St., District 5, 050085 Bucharest, Romania

8 Biological Sciences Division, The Romanian Academy, 25, Calea Victoriei, Sector 1, District 1, 010071 Bucharest, Romania

* Correspondence: beuranmircea@gmail.com

\begin{abstract}
In this study, we develop chitosan-hydroxyapatite (CS-HAp) composite layers that were deposited on Si substrates in radio frequency (RF) magnetron sputtering discharge in argon gas. The composition and structure of CS-HAp composite layers were investigated by analytical techniques, such as Fourier transform infrared spectroscopy (FT-IR), scanning electron microscopy (SEM), metallographic microscopy (MM), and atomic force microscopy (AFM). On the other hand, in the present study the second order derivative of FT-IR-ATR spectra, for compositional analyses of CS-HAp, were used. The SEM, MM, and AFM data have shown the formation of CS-HAp composite layers. The surface of CS-HAp composite layers showed uniform growth (at an Ar gas working pressure of $p=2 \times 10^{-3} \mathrm{mbar}$ ). The surface of the CS-HAp composites coatings became more nanostructured, becoming granular as the gas pressure increased from $5 \times 10^{-3}$ to $1.2 \times 10^{-2}$ mbar. However, our studies revealed that the surface morphology of the CS-HAp composite layers varies with the Ar gas working pressure. At the same time, optical properties are slightly influenced by Ar pressure. Their unique physicochemical properties make them suitable for various applications in the biomedical field, if we consider the already proven antimicrobial properties of chitosan. The antifungal properties and the capacity of the CS-HAp composite layers to inhibit the development of fungal biofilms were also demonstrated using the Candida albicans ATCC 10231 (C. albicans) fungal strain.
\end{abstract}

Keywords: chitosan; hydroxyapatite; coatings; morphology

\section{Introduction}

Hybrid coatings based on hydroxyapatite are of interest in research areas such as biomedicine or biomedical applications [1-3]. Hydroxyapatite ((HAp), $\left.\mathrm{Ca}_{10}\left(\mathrm{PO}_{4}\right)_{6}(\mathrm{OH})_{2}\right)$ is a calcium phosphate mineral widely present in human body [4], bioactive and biocompatible, and with the ability to accelerate the regeneration process of bones. It is extensively used to cover metal implants in order to increase their bioactivity and bone formation and 
regeneration. As it has a $\mathrm{Ca} / \mathrm{P}$ ratio similar to human bone, it can promote the formation of chemical bonds with the bone [4].

The biological properties, as well as the physicochemical ones, of HAp can be improved by it synthesis with chitosan [4-6]. Chitosan $\left(\left(\mathrm{C}_{6} \mathrm{H}_{11} \mathrm{NO}_{4}\right)_{\mathrm{n}}\right)$ is a natural polysaccharide with biofunctionality, non-toxicity, and antibacterial and biocompatible properties, with medical applications for scaffolds or coatings [4-7]. Chitosan has a broad antimicrobial activity against bacteria and fungi, the efficiency depending on the microorganism type [8]. Chitosan acts against microbes at the extracellular level, intracellular level [8], or both. High-molecular-weight chitosan acts only at the extracellular level, while low-molecularweight chitosan can also act at the intracellular level. Chitosan has antimicrobial action on both Gram-positive and Gram-negative bacteria [8].

The antifungal activity of chitosan against plant and human fungal pathogens has been proven to be attributed to its interaction with the cell wall and cell membranes [8-10], disrupting the cell structure or chelating ions or nutrients. Nevertheless, other methods that could be successfully used to treat bacterial contamination in various fields are represented by low-temperature plasma (LTP) physics, as previously reported [11-16].

The combination of hydroxyapatite with chitosan leads to an organic-inorganic composite material with improved biocompatibility and bone regeneration and antimicrobial properties [17-20]. By micro-arc oxidations chitosan-hydroxyapatite samples have been obtained with antimicrobial activity against Escherichia coli [9]. Scaffolds of mesoporous hydroxyapatite/chitosan produced by a hydrothermal method were helpful in periodontal regeneration and against periodontal pathogens [10]. Hybrid chitosan-hydroxyapatite (CS-HAp) coatings on different substrates were synthetized by: electrophoretic deposition [21], spin coating technique [22], plasma spraying [23], electrochemical deposition [21], or radio frequency magnetron sputtering discharges [24].

In $[24,25]$, the synthesis of hydroxyapatite-based coatings on metal or dielectric substrates was reported, as well as hybrid chitosan-hydroxyapatite coatings produced by magnetron sputtering technique [24]. This technique can be used for the fabrication of composite, inorganic, or polymer layers $[1,3,24,25]$. The hydroxyapatite or hydroxyapatitechitosan layers produced by this plasma method have good adhesion to the substrate, preserving the apatite structure of the sputtering target [24,25]. The addition of chitosan into the sputtering target conduces to the formation of surfaces with grain-like structures of variable sizes, from nanometers to microns. In our previous paper [24], we showed that the patterning of the surface of chitosan-hydroxyapatite coatings can be controlled by plasma deposition parameters.

The plasma polymers are of great interest for different biomedical applications [26], as their presence in a composite coating leads to the formation of nanoporous and nanostructured films. The physicochemical features of composite coatings generated by plasmabased methods cannot be reproduced by other chemical methods [26,27]. In the paper [9] it was proved that the microstructuring or nanostructuring of the surface topography of the prosthesis material interlayer promoted a better bone regeneration.

It is well known that one of the most implicated fungi in postoperative and nosocomial infections is Candida albicans [28]. Previous studies conducted by Iconaru S.L. and coworkers have shown that hydroxyapatite coatings deposited on various substrates do not protect from C. albicans colonization and biofilm development [29]. Therefore, we chose to use chitosan as proven large spectrum antimicrobial agent [30]. There have been many studies conducted on hydroxyapatite-chitosan composite powders/scaffolds [17-20] but only few on CS-HAp coatings (especially on the influence of the Ar gas working pressure on the physicochemical properties) [24]. Due to the lack of studies on the hydroxyapatitechitosan coatings, we chose to conduct, for the first time, complex studies regarding the influence of Ar gas working pressure on the surface topography of novel CS-HAp coatings for biomedical application. Moreover, the use of these new coatings in applications such as implantology could improve host cells adhesion and simultaneously reduce the risk of microbial infection compared to hydroxyapatite-chitosan composite powders [24]. 
The present study attempted to obtain the CS-HAp composite layers and analyze their morphological and optical properties. The major objective of the present work is to use chitosan-hydroxyapatite as a starting material for the fabrication of CS-HAp composite layers by radio frequency (RF) magnetron sputtering discharge in argon gas. Thus, for obtaining the coatings, chitosan was selected as a biopolymer and an antimicrobial agent. The CS-HAp coatings were obtained by radio frequency magnetron sputtering at various argon (Ar) gas working pressures. The obtained composite coatings were investigated from the physicochemical point of view by Fourier transform infrared spectroscopy (FT-IR), scanning electron microscopy (SEM), atomic force microscopy (AFM), and metallographic microscopy (MM).

\section{Materials and Methods}

\subsection{Materials}

Chitosan-coated hydroxyapatite (CS-HAp) powders were obtained by an adapted coprecipitation method using $\mathrm{Ca}\left(\mathrm{NO}_{3}\right)_{2} \cdot 4 \mathrm{H}_{2} \mathrm{O}$ (calcium nitrate tetrahydrate, Sigma Aldrich, St. Louis, MO, USA, $\geq 99.0 \%$ ), $\left(\mathrm{NH}_{4}\right)_{2} \mathrm{HPO}_{4}$ (ammonium hydrogen phosphate, Sigma Aldrich, St. Louis, $\mathrm{MO}, \mathrm{USA}, \geq 99.0 \%$ ), $\mathrm{NH}_{4} \mathrm{OH}$ (ammonium hydroxide, Sigma Aldrich, St. Louis, MO, USA, $25 \% \mathrm{NH}_{3}$ in $\mathrm{H}_{2} \mathrm{O}$ ), chitosan (Sigma Aldrich, St. Louis, MO, USA) polymer of low (CSL) molecular weight, $\mathrm{CH}_{3} \mathrm{COOH}$ (acetic acid, Sigma Aldrich, St. Louis, $\mathrm{MO}, \mathrm{USA}, \geq 99.7 \%$ ) $\mathrm{C}_{2} \mathrm{H}_{5} \mathrm{OH}$ (ethanol absolute, Merck, NJ, USA, $\geq 99.5 \%$ ), and deionized water. All products were used in synthesis without any further purification. Deionized water was used in order to prepare all of the reactive solutions.

\subsection{Synthesis of Chitosan-Hydroxyapatite Composites and Deposited Layers}

To synthesize the chitosan-hydroxyapatite composites (CS-HAp, Ca/P ratio was equal to 1.67), the chitosan solutions were obtained by dissolving $0.4 \mathrm{~g}$ of chitosan powder in acetic acid solution ( $2 \mathrm{wt} . \%)$. In the first step, the aqueous solution of $\mathrm{Ca}\left(\mathrm{NO}_{3}\right)_{2} \cdot 4 \mathrm{H}_{2} \mathrm{O}$ was mixed with chitosan solution in the ratio 3:2. In the second step, $\left(\mathrm{NH}_{4}\right)_{2} \mathrm{HPO}_{4}$ solution was added drop by drop. The ammonium hydroxide solution was used to maintain the $\mathrm{pH}$ at 10. Further, the resulting precipitate was filtered and washed five times and finally dried at $150^{\circ} \mathrm{C}$ to obtain CS-HAp composite powders. The CS-HAp composite powders were used to produce a target of 2 inches in diameter by mechanical pressing. The target was dried for $2 \mathrm{~h}$ at $150{ }^{\circ} \mathrm{C}$.

The CS-HAp composite layers were obtained accordingly with previous studies [24]. The Ar working pressure and the name of the samples are presented in Table 1 [24]. The composite layers were deposited on Si substrates in radio frequency (RF) magnetron sputtering discharge in argon gas [31].

Table 1. Ar working pressure and the associated name of the obtained coatings.

\begin{tabular}{cc}
\hline Ar Gas Working Pressure (mbar) & Sample Name \\
\hline $2 \times 10^{-3}$ & CS-HAp_1 \\
$5 \times 10^{-3}$ & CS-HAp_2 \\
$1.2 \times 10^{-2}$ & CS-HAp_3 \\
\hline
\end{tabular}

\subsection{Characterization of CS-HAp Composite Layers}

\subsubsection{Fourier Transform Infrared Spectroscopy (FT-IR)}

The functional groups presented in the synthesized CS-HAp coatings were identified using a Perkin Elmer SP-100 spectrometer (Waltham, MA, USA) operating in "attenuated total reflection" (ATR) mode. The transmittance spectra were acquired in the $400-4000 \mathrm{~cm}^{-1}$ spectral range and with a resolution of $4 \mathrm{~cm}^{-1}$ and 256 scans. The obtention of second derivative spectra is described in detail in [32]. The second derivative spectra were used, mainly to increase the separation of the overlapped bands and to better highlight the chemical links between hydroxyapatite and chitosan. 


\subsubsection{Scanning Electron Microscopy (SEM-EDX)}

The surface morphology and elemental analysis of the obtained coatings were characterized using a Quanta Inspect F (Thermo Fisher, Waltham, MA, USA) equipped with an energy-dispersive $X$-ray spectrometer (EDAX). The 3D reconstruction of the 2D SEM micrographs was performed using Image J software (ImageJ 1.51j8, National Institutes of Health, Bethesda, MD, USA) [33].

\subsubsection{Metallographic Microscopy}

More information about the morphology of the CS-HAp coatings was obtained by metallographic microscopy. Metallographic images at $10 \times$ magnification were obtained with the aid of an inversed trinocular metallographic microscope OX.2153-PLM (Euromex, Arnhem, The Netherlands). The 3D representation of the 2D metallographic images was performed using Image J software (ImageJ 1.51j8, National Institutes of Health, Bethesda, MD, USA) [33].

\subsubsection{Atomic Force Microscopy (AFM)}

The surface topography of the obtained CS-HAp coatings was also studied by atomic force microscopy (AFM). A NT-MDT NTEGRA Probe Nano Laboratory instrument (NTMDT, Moscow, Russia) operating in non-contact mode (at room temperature) using a silicon NT-MDT NSG01 cantilever (NT-MDT, Moscow, Russia) coated with a $35 \mathrm{~nm}$ gold layer was used in order to obtain the AFM images. The AFM topography was acquired on a surface area of $5 \times 5 \mu^{2}$. All of the obtained AFM images were processed with the Gwyddion 2.59 software (Department of Nanometrology, Czech Metrology Institute, Brno, Czech Republic) [34], and the root mean square roughness ( $\mathrm{R}_{\mathrm{RMS}}$ ) was also determined.

\subsubsection{In Vitro Antifungal Activity}

The qualitative antifungal activity of the obtained composite layers was evaluated determined using Candida albicans ATCC 10231 (C. albicans) fungal strain. For this purpose, $500 \mu \mathrm{L}$ of microbial suspension of $C$. albicans, having $\sim 5 \times 10^{6}$ colony forming units $(\mathrm{CFU}) / \mathrm{mL}$ obtained from $24 \mathrm{~h}$ microbial cultures, was grown on the composite layers immersed in $4 \mathrm{~mL}$ culture medium (liquid yeast peptone glucose, YPG). After 24, 48, and $72 \mathrm{~h}$, the composite thin films were removed from the culture medium, washed using sterile saline solution for the removal of unattached fungal cells, then fixed in cold methanol and prepared for scanning electron microscopy (SEM) and confocal laser scanning microscopy (CLSM) studies. For CLSM visualization, the specimens were stained before visualization for 5 min with ethidium bromide and visualized in reflection and fluorescence modes using a TCS SP confocal microscope (Leica, Wetzlar, Germany) equipped with a 10X HCX PL FLUORITE objective with a numerical aperture NA of 0.3. An Ar-ion laser (488 nm) was also used to simultaneously acquire both reflection and fluorescence images. The quantitative antifungal properties were determined with the aid of fungal suspensions of a known fungal density $\left(\sim 5 \times 10^{6}\right.$ colony forming units $\left.(\mathrm{CFU}) / \mathrm{mL}\right)$ obtained from $24 \mathrm{~h}$ fungal cultures. The samples were incubated at $37^{\circ} \mathrm{C}$ for $72 \mathrm{~h}$ with the fungal suspensions in order to evaluate the temporal dynamics of the fungal cells' development after 24, 48, and $72 \mathrm{~h}$. For this purpose, for each intended incubation time $(24,48$, and $72 \mathrm{~h})$ the microbial suspensions were collected and incubated for $24 \mathrm{~h}$ on LB agar medium. A free microbial suspension was used as positive control $(\mathrm{C}+)$. The number of colony forming units per milliliter $(\mathrm{CFU} / \mathrm{mL})$ was determined and presented graphically as LogCFU.ml function of time. The experiments were performed in triplicate, and the results were expressed as mean \pm standard deviation (SD). The statistical analysis of the data was performed using ANOVA single factor test. Furthermore, a viable cell count (VCC) assay of the fungal cells was also performed in order to assess the viable fungal cells. For this purpose, the composite layers were added in a sterile saline solution inoculated with microbial suspensions having a $\sim 5 \times 10^{6} \mathrm{CFU} / \mathrm{mL}$ concentration. The samples were incubated under stirring at $37^{\circ} \mathrm{C}$ for $72 \mathrm{~h}$. The number of viable fungal cells was determined using $10 \mu \mathrm{L}$ 
of fungal suspension at 24,48 , and $72 \mathrm{~h}$. For this purpose, the fungal suspensions were further diluted, and $10 \mu \mathrm{L}$ of each serial dilution was plated in duplicate on LB agar. After $24 \mathrm{~h}$ of incubation at $37^{\circ} \mathrm{C}$, viable cell counts were performed, and the number of $\mathrm{CFU} / \mathrm{mL}$ for each sample was evaluated.

\section{Results and Discussions}

The presence of functional groups in the obtained CS-HAp_1, CS-HAp_2, and CSHAp_3 coatings was investigated using Fourier transform infrared spectroscopy (FT-IR). The results of FT-IR studies are presented in Figure 1a-c. In the obtained FT-IR spectra, there could be noticed the presence of the vibrational bands characteristic of the hydroxyapatite (HAp) structure $\left(\mathrm{OH}^{-}\right.$and $\mathrm{PO}_{4}{ }^{3-}$ groups) as well as those specific to the chitosan structure $(\mathrm{N}-\mathrm{H}, \mathrm{C}-\mathrm{H}, \mathrm{C}-\mathrm{O}$, and $\mathrm{C}=\mathrm{O})$. Thus, because the Ar gas working pressure induced a slight displacement of the vibrational bands, below are presented only the results obtained for CS-HAp ( $\left.p=2 \times 10^{-3} \mathrm{mbar}\right)$, the other obtained FT-IR spectra being similar. Therefore, in the vibrational band present at around $3551 \mathrm{~cm}^{-1}$, two bands specific to $\mathrm{OH}$ vibration from HAp structure and to amine symmetric vibration from chitosan structure, respectively, are overlapping $[24,35,36]$. The main vibrational bands present in the $2800-2970 \mathrm{~cm}^{-1}$ spectral region were characteristic of $\mathrm{CH}$ stretching vibration $[6,24,35,36]$. The presence of $v_{3} \mathrm{CO}_{3}{ }^{2-}$ vibrational groups in the samples was highlighted by the presence in the FT-IR spectra of a band at around $1461 \mathrm{~cm}^{-1}$ (Figure 1a-c). In addition, in the spectral region $400-1100 \mathrm{~cm}^{-1}$ could be noticed vibrational bands specific to phosphate groups $\left(v_{3}, v_{4}\right.$, and $\left.v_{1}\left(\mathrm{PO}_{4}{ }^{3-}\right)\right)$ from HAp structure [35]. Thus, the peaks at around 1020 and $938 \mathrm{~cm}^{-1}$ are specific to $v_{3}\left(\mathrm{PO}_{4}{ }^{3-}\right)$ and $v_{1}\left(\mathrm{PO}_{4}{ }^{3-}\right)$, respectively (Figure 1a-c) [24]. Moreover, the presence of $v_{4}$ $\left(\mathrm{PO}_{4}{ }^{3-}\right)$ in the samples was demonstrated by the presence of peaks at around 558 and $674 \mathrm{~cm}^{-1}[24,32]$. Furthermore, it can be observed that in the case of layers deposited at $2 \times 10^{-3}$ mbar Ar gas working pressure, the peaks are slightly displaced and broadened compared to the peaks obtained in the case of samples obtained at $1 \times 10^{-2} \mathrm{mbar} \mathrm{Ar}$ gas working pressure (Figure $1 \mathrm{a}-\mathrm{c}$ ). On the other hand, the FT-IR results confirmed the presence of bonds between the phosphate/hydroxyl groups specific to HAp structure and those characteristic of chitosan (amine, etc.) (Figure 1a-c).

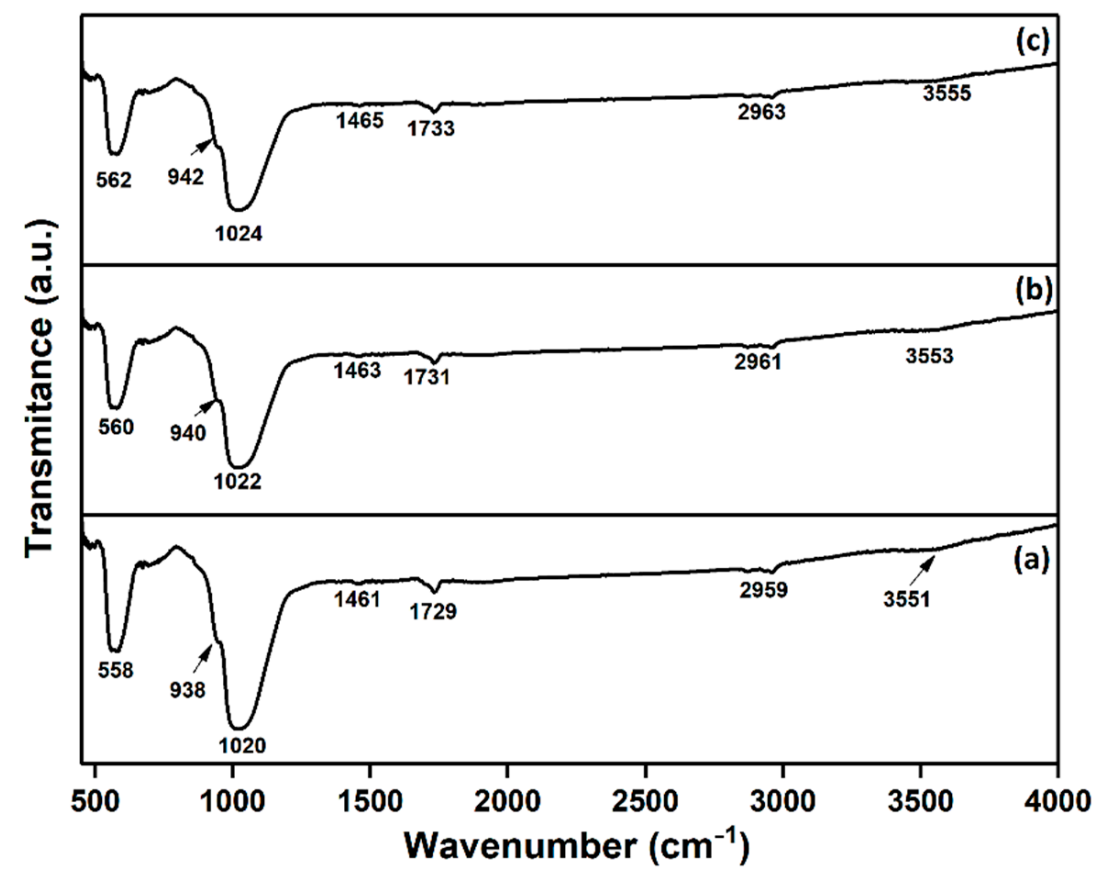

Figure 1. FT-IR spectra of CS-HAp coatings at: (a) $p=2 \times 10^{-3}$ mbar; (b) $p=5 \times 10^{-3}$ mbar; (c) $p=1.2 \times 10^{-2}$ mbar. 
It is well known that second derivative spectra can bring valuable information regarding the change in structure of studied samples. Therefore, for a better observation of overlapped bands, the second derivative spectra (in the $450-1100 \mathrm{~cm}^{-1}$ and $1300-3000 \mathrm{~cm}^{-1}$ spectral regions) of CS-HAp_1, CS-HAp_2, and CS-HAp_3 are presented in Figure 2. The second derivative spectra obtained between $450-1100 \mathrm{~cm}^{-1}$ (Figure 2a,c,e) clearly highlight the presence of the vibrational bands (at $450-700 \mathrm{~cm}^{-1}$ and $900-1100 \mathrm{~cm}^{-1}$ ) associated with $v_{4}, v_{1}$, and $v_{3}\left(\mathrm{PO}_{4}{ }^{3-}\right)$ from HAp structure [32]. The bands present at around $1377,1460,2856$, and $2956 \mathrm{~cm}^{-1}$ are attributed to $\mathrm{C}-\mathrm{H}$ vibration from chitosan structure (Figure $2 b, d, f)[35,36]$. The bending vibration of $v \mathrm{NH}_{2}$ observed around $1520 \mathrm{~cm}^{-1}$ belongs to that of a main group from the chitosan structure-glucosamide [6,35]. Other vibrational bands from $700-500 \mathrm{~cm}^{-1}$ and $1100-1000 \mathrm{~cm}^{-1}$, which could belong either to $\mathrm{C}-\mathrm{H} / \mathrm{C}-\mathrm{O}$ bonds or to $\mathrm{PO}_{4}{ }^{3-}$, may indicate the interaction bonds between HAp and chitosan $[6,24,35,36]$. Therefore, we notice that the increase in Ar gas working pressure from $2 \times 10^{-3}$ mbar to $1.2 \times 10^{-2}$ mbar induced a slight displacement of the vibrational bands present in the analyzed coatings.
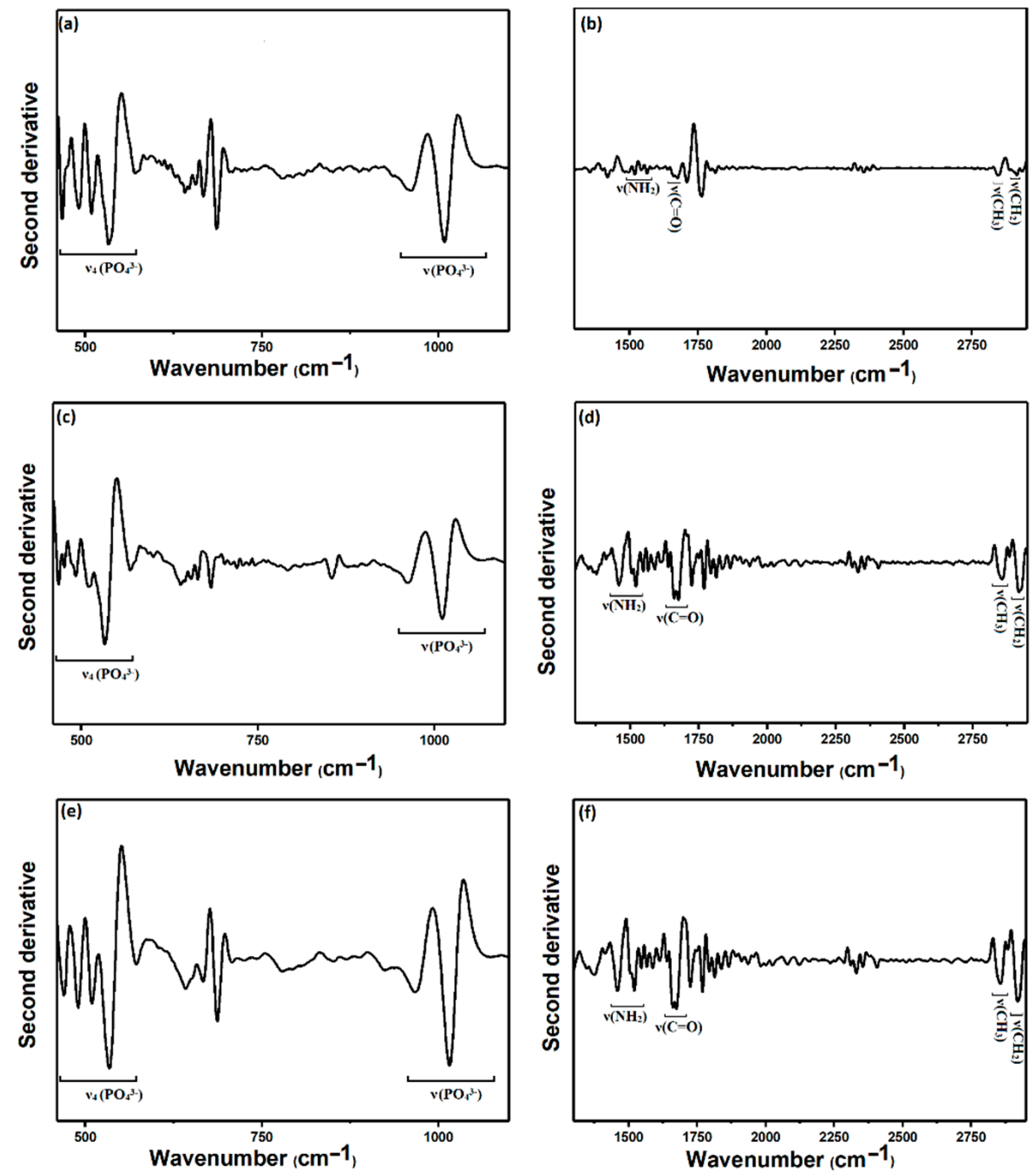

Figure 2. Second derivative spectra of CS-HAp coatings obtained at: $p=2 \times 10^{-3} \mathrm{mbar}(\mathbf{a}, \mathbf{b})$; $p=5 \times 10^{-3} \operatorname{mbar}(\mathbf{c}, \mathbf{d}) ; p=1.2 \times 10^{-2} \operatorname{mbar}(\mathbf{e}, \mathbf{f})$.

Therefore, we can conclude that our results are in good agreement with the studies reported by Dreghici B.D. and colleagues [24].

Scanning electron microscopy (SEM) was used in order to study the influence of Ar gas working pressures on the surface morphology of CS-HAp coatings. The 2D SEM 
micrographs specific to the obtained CS-HAp coatings, along with their 3D representation, are presented in Figure 3. In the case of the CS-HAp coatings obtained at an Ar gas working pressure of $p=2 \times 10^{-3}$ mbar, there could be noticed a smooth surface which showed a uniform growth (Figure 3a). Moreover, as the working gas pressure increased, it was observed that the surface of the coatings became more nanostructured, becoming granular. Therefore, at high pressures ( $\left.p=1.2 \times 10^{-2} \mathrm{mbar}\right)$, the surface morphology of the coatings is granular (Figure 3e). According to previous studies, these variations in the surface morphology of the coatings may be due to the polymerization process [24]. The 3D reconstruction of SEM images revealed the increase of granular structure with the increase of Ar gas working pressure (Figure 3b,d,f). Moreover, SEM micrographs do not show the presence of fractures, cracks, or other discontinuities on the surface of the analyzed samples.
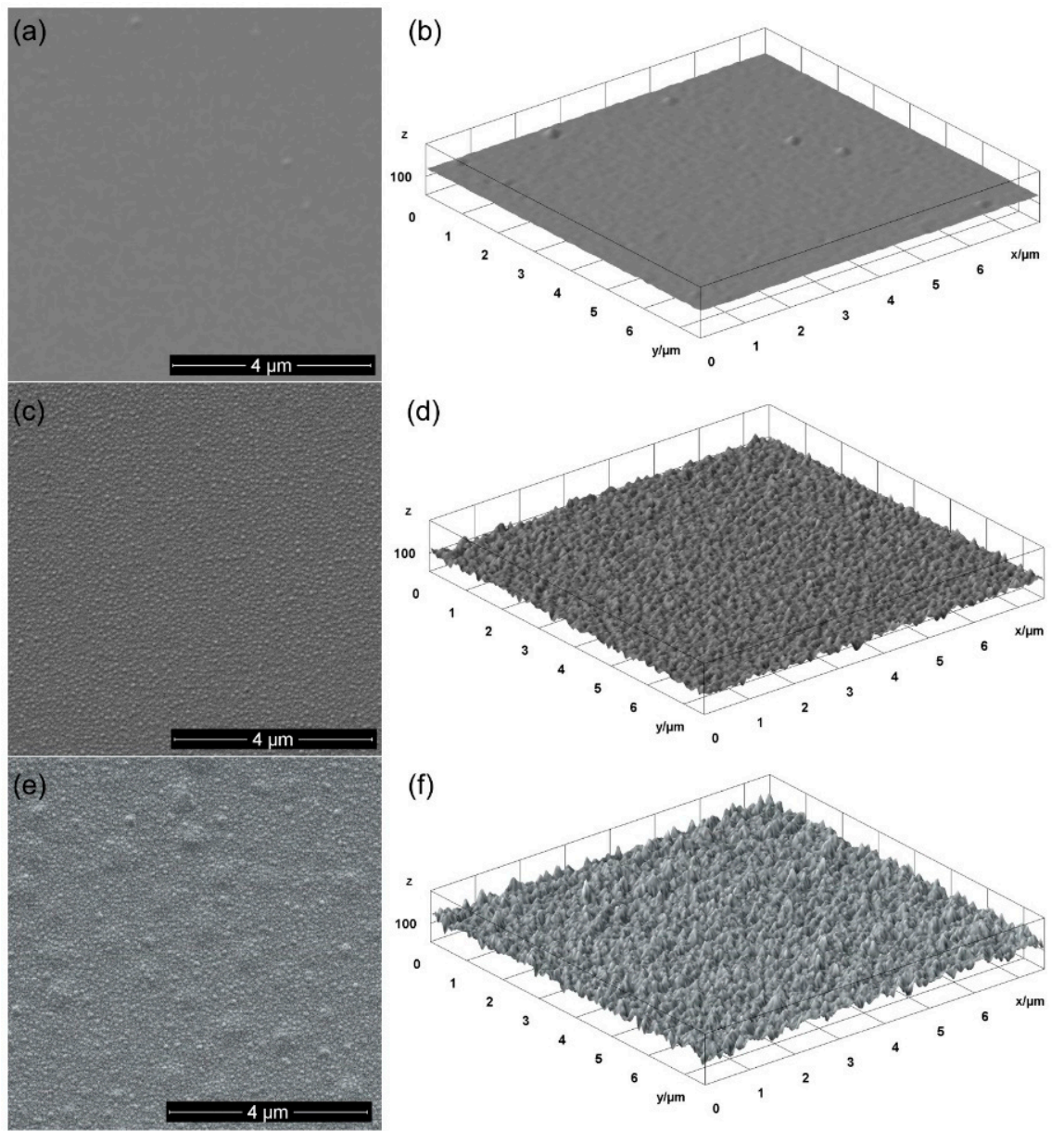

Figure 3. 2D SEM micrograph of CS-HAp coatings obtained at: $p=2 \times 10^{-3} \mathrm{mbar}(\mathbf{a})$; $p=5 \times 10^{-3} \operatorname{mbar}(\mathbf{c}) ; p=1.2 \times 10^{-2} \operatorname{mbar}(\mathbf{e})$. 3D representation of SEM images obtained on CS-HAp coatings: $p=2 \times 10^{-3} \operatorname{mbar}(\mathbf{b}) ; p=5 \times 10^{-3} \operatorname{mbar}(\mathbf{d}) ; p=1.2 \times 10^{-2} \operatorname{mbar}(\mathbf{f})$.

The chemical composition of CS-HAp coatings was investigated by EDX studies. Also, elemental mapping of the coatings' surfaces was recorded. The results of EDX studies along with the specific elemental mapping are revealed in Figures 4-6. In all the studied samples in the obtained EDX spectra, the following main chemical elements are present: carbon, nitrogen, oxygen, phosphorous, and calcium. All these elements are characteristic of the CS-HAp coatings. The Si line from the EDX spectra is produced by the substrate on which the coatings were deposited. On the other hand, the elemental mapping revealed the uniform and homogeneous distribution of $\mathrm{Ca}, \mathrm{P}, \mathrm{O}, \mathrm{N}$, and $\mathrm{C}$ on the samples. Furthermore, no additional chemical elements could be noticed in the EDX spectra, which suggests 
purity of the analyzed samples. It could be observed that the Ar gas working pressure slightly influenced the chemical composition of the analyzed samples.

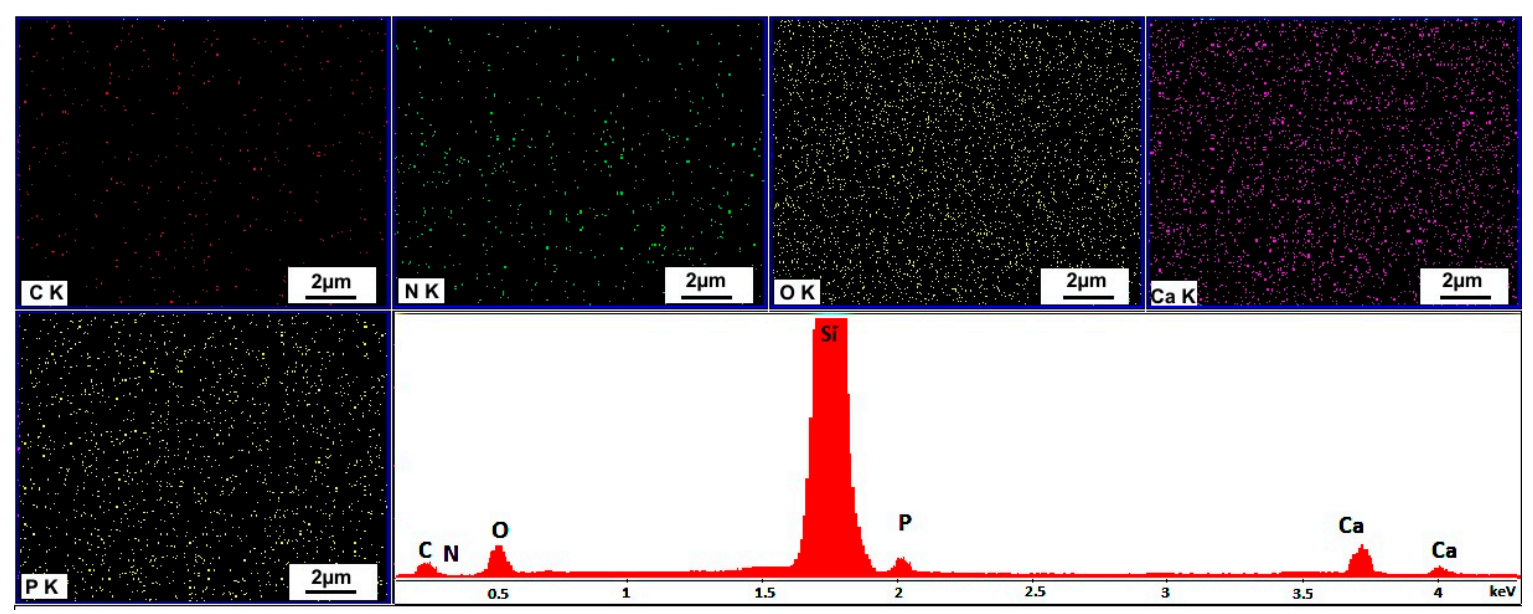

Figure 4. Elemental mapping and typical EDX spectrum of CS-HAp coatings obtained at $p=1.2 \times 10^{-2}$ mbar.

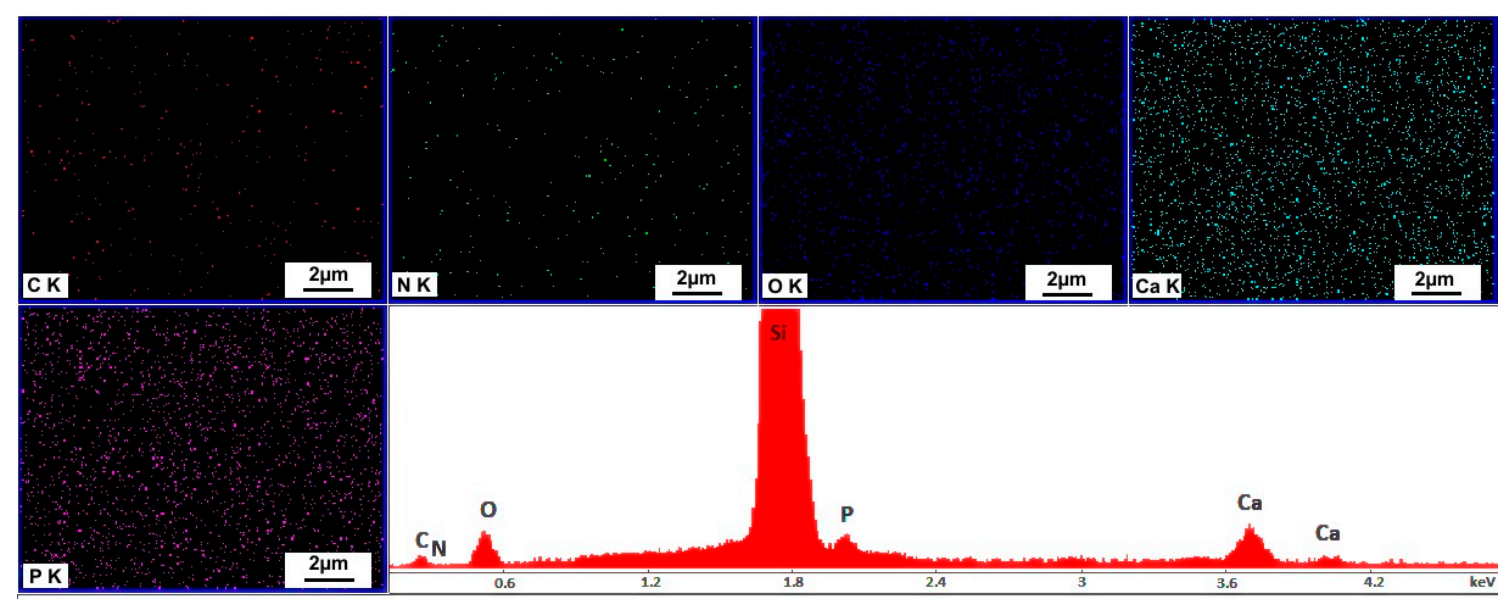

Figure 5. Elemental mapping and typical EDX spectrum of CS-HAp coatings obtained at $p=5 \times 10^{-3}$ mbar.

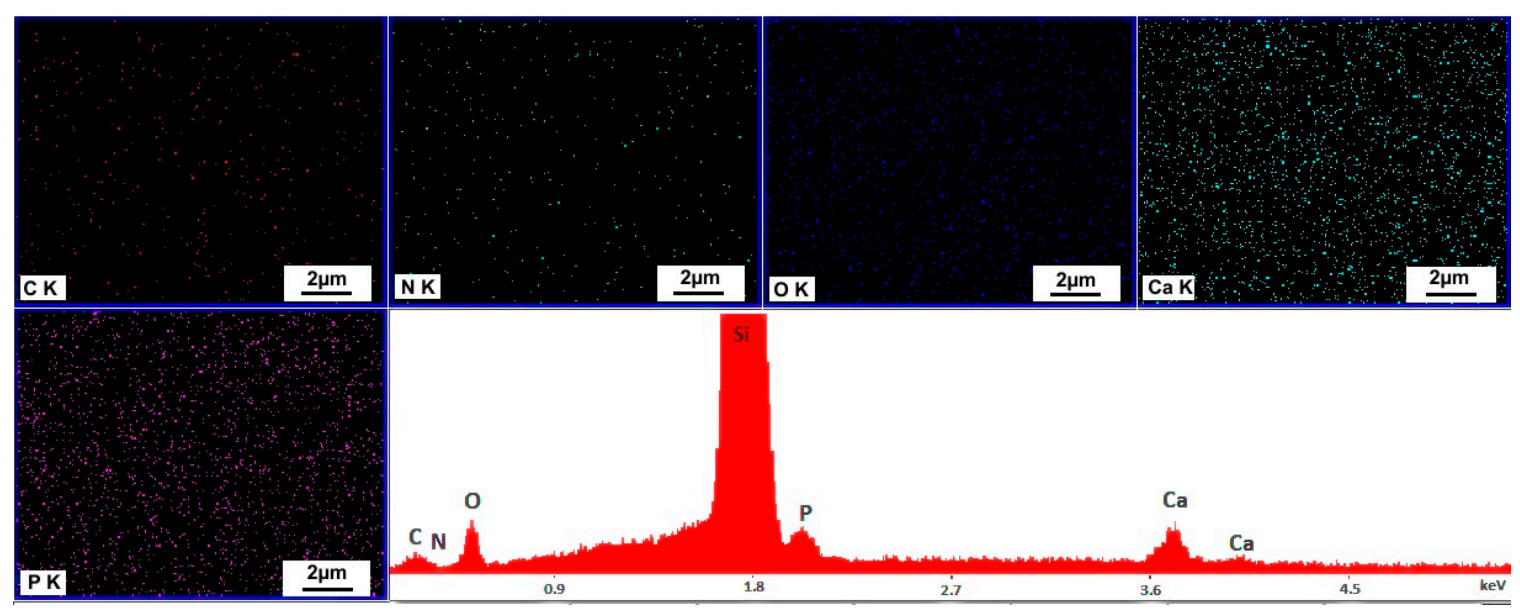

Figure 6. Elemental mapping and typical EDX spectrum of CS-HAp coatings obtained at $p=2 \times 10^{-3}$ mbar.

The characteristic 2D metallographic microscopy images and their 3D reconstruction of the CS-HAp coatings are depicted in the metallographic Figure 7. By this technique, 
complementary information is obtained about the surface topography of the CS-HAp coatings. As well as SEM studies, the information obtained by metallographic microscopy (at 10× magnification) is similar. Thus, the absence of cracks, fissures, or other defects is also confirmed by metallographic microscopy images. Moreover, the change of the surface morphology is confirmed with the increase in working gas pressure. Thus, it is observed that in the case of the coatings obtained at a low pressure $\left(p=2 \times 10^{-3}\right.$ mbar, Figure 7a) the surface morphology is uniform and smooth, while in the case of coatings obtained at higher pressures a structuring of the surface is observed. Thus, in the case of the coatings obtained at $p=5 \times 10^{-3}$ mbar (Figure 7c) and $p=1.2 \times 10^{-2} \mathrm{mbar}$ (Figure 7e), a granular morphology of the surface is observed, which increases with the increase of the gas (Ar) working pressure. The 3D representations of metallographic microscopy images underline the surface coating modification (from smooth to granular) with the increase in working gas (Ar) pressure and, on the other hand, their uniformity and continuity.



Figure 7. 2D Metallographic images (at $10 \times$ magnification) of CS-HAp coatings obtained at: $p=2 \times 10^{-3} \operatorname{mbar}(\mathbf{a}) ; p=5 \times 10^{-3} \operatorname{mbar}(\mathbf{c}) ; p=1.2 \times 10^{-2} \mathrm{mbar}(\mathbf{e})$. 3D representation of metallographic images obtained on CS-HAp coatings: $p=2 \times 10^{-3} \operatorname{mbar}(\mathbf{b}) ; p=5 \times 10^{-3} \mathrm{mbar}(\mathbf{d})$; $p=1.2 \times 10^{-2} \operatorname{mbar}(\mathbf{f})$.

Additional information regarding the surface topography of the CS-HAp coatings obtained at various Ar gas working pressures $\left(p=2 \times 10^{-3}\right.$ mbar; $p=5 \times 10^{-3}$ mbar; $p=1.2 \times 10^{-2}$ mbar) was obtained by AFM investigation. Specific AFM topographies of the CS-HAp coatings are presented in Figure 8. Thus, for the CS-HAp coatings obtained at a $p=2 \times 10^{-3}$ mbar, the AFM images show that they possess a smooth surface morphology (Figure 8a,b). A granular surface morphology was noticed in the case of the coatings deposited at higher Ar gas working pressures $\left(p=5 \times 10^{-3}\right.$ mbar and $p=1.2 \times 10^{-2} \mathrm{mbar}$ ). An increase of granular structured could also be observed. On the other hand, the 3D rep- 
resentation of AFM topographies emphasizes similar modification, as previously noticed in the $2 \mathrm{D}$ representation.
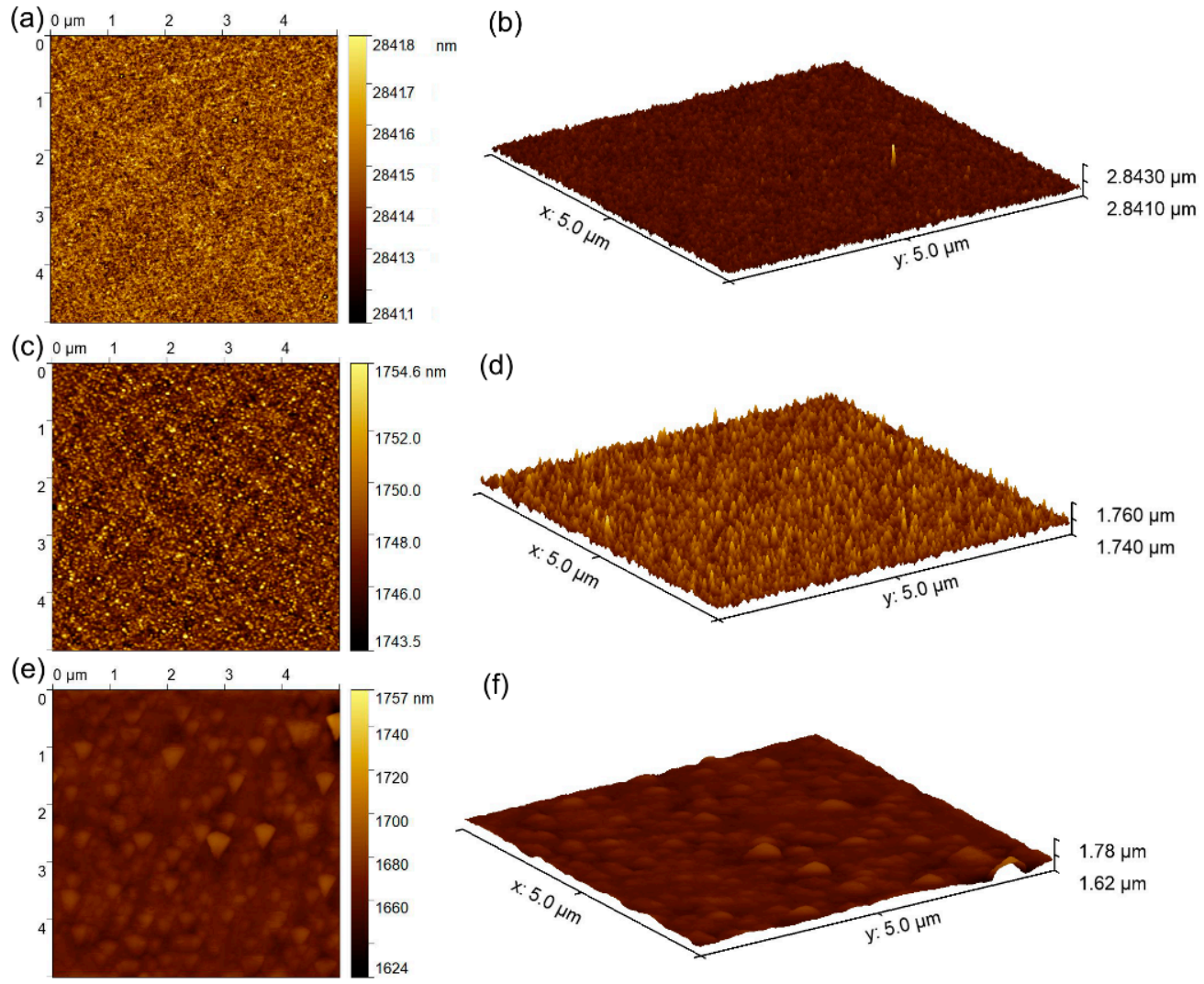

(f)



Figure 8. 2D AFM topography of CS-HAp coatings obtained at: $p=2 \times 10^{-3}$ mbar (a); $p=5 \times 10^{-3}$ mbar (c); $p=1.2 \times 10^{-2}$ mbar (e). 3D representation of AFM topography obtained on CS-HAp coatings: $p=2 \times 10^{-3} \operatorname{mbar}(\mathbf{b}) ; p=5 \times 10^{-3} \operatorname{mbar}(\mathbf{d}) ; p=1.2 \times 10^{-2} \operatorname{mbar}(\mathbf{f})$.

On the other hand, the root mean square roughness ( $R_{R M S}$ ) values obtained for the analyzed samples are presented in Table 2 . The obtained $R_{R M S}$ values confirm the results obtained by visual investigation of the samples surface regarding the increase in granular morphology (and, consequently, the surface roughness) as the working gas pressure increases. Therefore, it could be underlined that the results obtained by AFM studies are in good agreement with the results obtained by the complementary methods, such as SEM and metallographic microscopy. Thus, our results support and are in good agreement with the results previously reported by Dreghici D.B. et al. [24] on the surface morphology of hydroxyapatite-chitosan composite coatings.

Table 2. Root mean square roughness ( $\mathrm{R}_{\mathrm{RMS}}$ ) values for the CS-HAp coatings.

\begin{tabular}{ccc}
\hline Sample & Ar Gas Working Pressure & $\mathbf{R}_{\mathbf{R M S}}$ \\
\hline CS-HAp_1 & $2 \times 10^{-3} \mathrm{mbar}$ & $0.112 \mathrm{~nm}$ \\
CS-HAp_2 & $5 \times 10^{-3} \mathrm{mbar}$ & $1.797 \mathrm{~nm}$ \\
CS-HAp_3 & $1.2 \times 10^{-2} \mathrm{mbar}$ & $6.051 \mathrm{~nm}$ \\
\hline
\end{tabular}

Qualitative assays regarding the adhesion and development of fungal cells on the surface of CS-HAp coatings were undertaken using SEM studies. The development of C. albicans microbial cells on the surface of the CS-HAp layers obtained at various Ar gas working pressures ( $p=2 \times 10^{-3}$ mbarr; $p=5 \times 10^{-3}$ mbarr; $p=1.2 \times 10^{-2}$ mbarr) were investigated at three different time intervals by SEM visualization. The images obtained 
by SEM visualization of the C. albicans microbial cells adhered on the surface of CS-HAp coatings after 24, 48, and $72 \mathrm{~h}$ of incubation are depicted in Figure 9. The SEM visualization in the case of the CS-HAp coatings incubated for 24,48 , and $72 \mathrm{~h}$ with C. albicans ATCC 10231 highlighted that the morphology of the fungal cells adhered on the surface of CS-HAp coatings was characteristic of the C. albicans fungal strain, having an ovaloid "yeast" shape and sizes ranging from 2.5 to $4.8 \mu \mathrm{m}$. The SEM images also reflect that the CS-HAp coatings presented a good inhibitory effect against the development of $C$. albicans fungal cells at all tested time intervals. The SEM images indicated that a better antimicrobial activity was observed in the case of CS-HAp coatings obtained at an Ar gas working pressure of $p=1.2 \times 10^{-2}$ mbarr for all tested time intervals. The SEM images accentuated that, for all of the time intervals, the CS-HAp coatings obtained at various Ar gas working pressures $\left(p=2 \times 10^{-3}\right.$ mbarr; $p=5 \times 10^{-3}$ mbarr; $p=1.2 \times 10^{-2}$ mbarr) had a strong inhibitory effect on the adherence and development of the C. albicans fungal cells. Nonetheless, a more substantial antibacterial activity of the CS-HAp coatings was identified after $72 \mathrm{~h}$ of incubation. Moreover, the data suggested that the CS-HAp_3 coatings were more effective in inhibiting cell adherence of C. albicans compared to CS-HAp_1 and CS-HAp_2 composite layers.
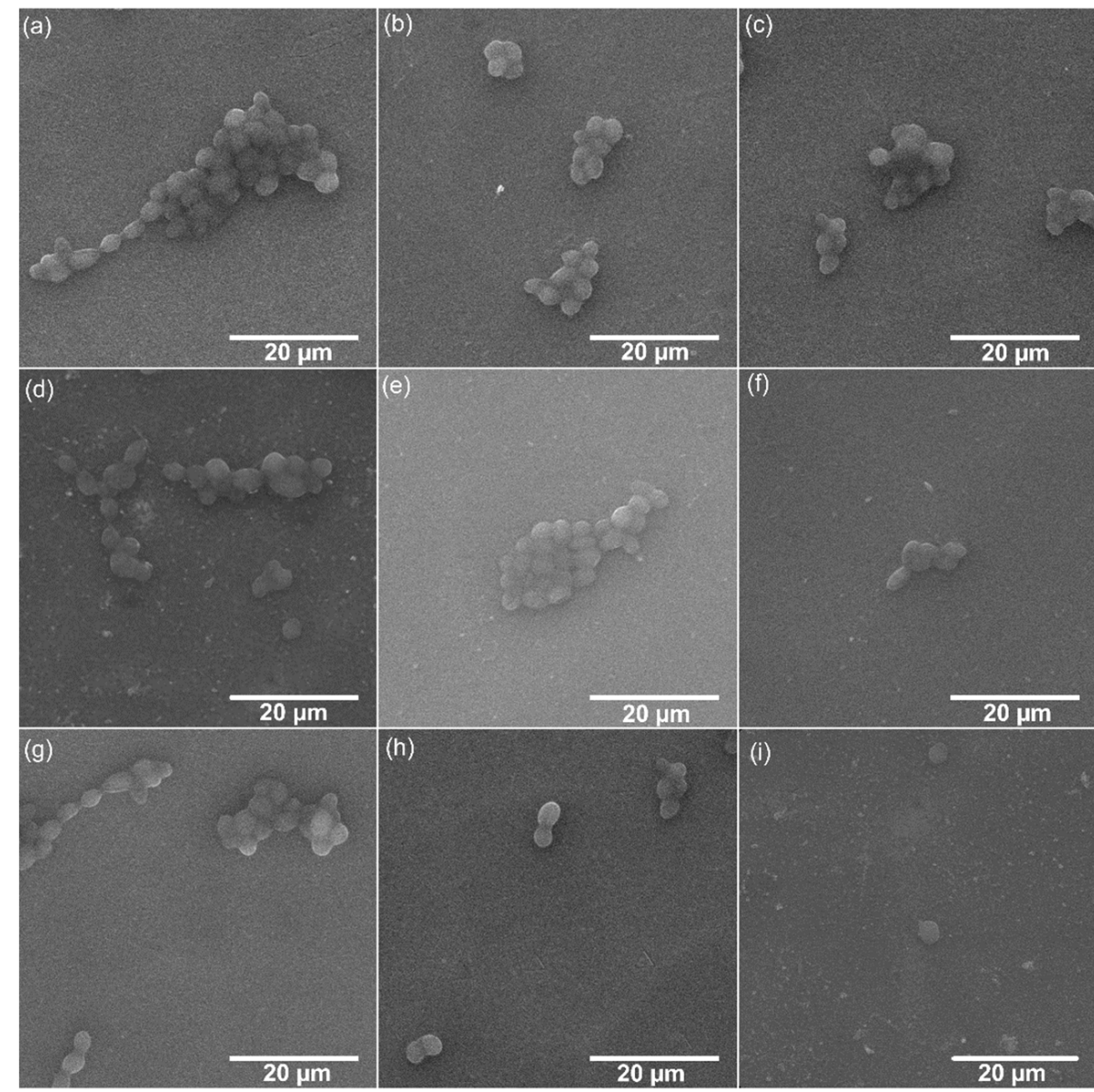

Figure 9. SEM images of Candida albicans ATCC 10231 cell development on the surface of CSHAp_1 (a-c), CS-HAp_2 (d-f), and CS-HAp_3 (g-i) after 24 h (a,d,g), 48 h (b,e,h), and 72 h (c,f,i) of incubation.

Furthermore, complementary information regarding the adhered fungal cells on the surface of CS-HAp composite layers was also obtained by CLSM visualization. The results of the CLSM studies are presented in Figure 10a-f. The results of the CLSM studies have emphasized that the fungal cells adhered on the surface of CS-HAp composite layers are sparsely distributed and do not present any major conglomerates, thus revealing that the 
composite layers were effective in inhibiting C. albicans biofilm formation. In addition, the CLSM images showed that the fungal cells attached to the CS-HAp coatings were distinctive to $C$. albicans fungal cell morphology, with sizes ranging from 2.37 to $4.72 \mu \mathrm{m}$ and having ovaloid shape. The data obtained by CLSM studies also emphasized that the antifungal properties of the CS-HAp layers were influenced by both the incubation time and the samples. The results suggested that CS-HAp_3 composite layers were the most effective in inhibiting the cell development and adherence of the fungal cells. Furthermore, the CLSM visualization confirmed the SEM results and evidenced that the CS-HAp were effective in inhibiting C. albicans cell development on their surface and also were able to prevent fungal biofilm formation. In addition, the results have confirmed that after $72 \mathrm{~h}$ of incubation the number of fungal cells still adhered on the surface of CS-HAp coatings was diminished, almost to extinction in the case of the CS-HAp_3 sample. The results depicted by the qualitative antifungal assays suggested that these types of composite coatings could be of great interest in the future development of antifungal medical devices.

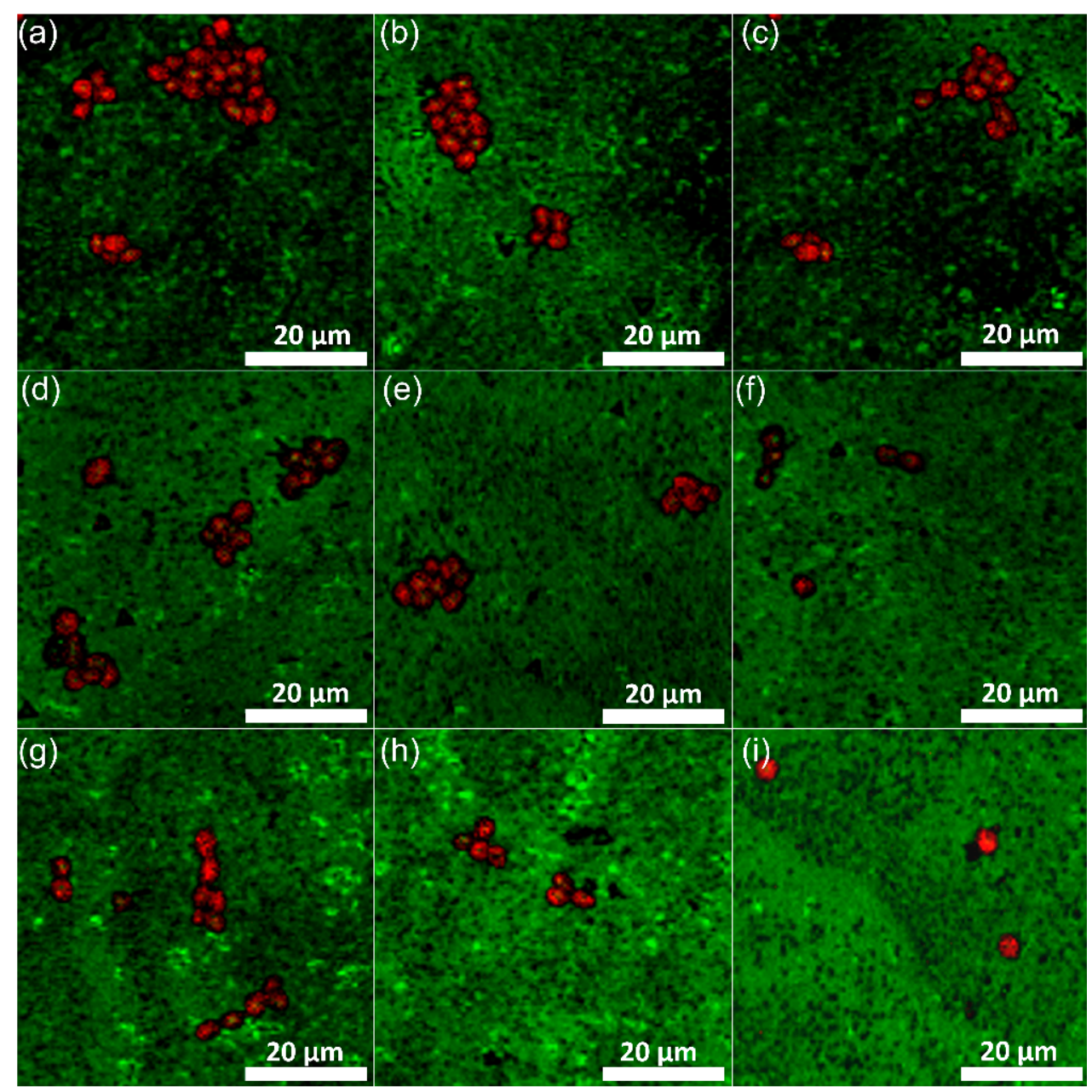

Figure 10. CLSM images of Candida albicans ATCC 10231 cell development on the surface of CSHAp_1 (a-c), CS-HAp_2 (d-f), and CS-HAp_3 (g-i) after 24 h (a,d,g), 48 h (b,e,h), and 72 h (c,f,i) of incubation.

Quantitative assays regarding the antifungal activity of the CS-HAp composite layers were also performed. The effects of the CS-HAp layers on C. albicans fungal cells were investigated at three different time intervals of incubation time (24, 48, and $72 \mathrm{~h})$. For this purpose, the three CS-HAp layers obtained at various Ar gas working pressures $\left(p=2 \times 10^{-3}\right.$ mbarr; $p=5 \times 10^{-3}$ mbarr; $p=1.2 \times 10^{-2}$ mbarr $)$ were incubated with the microbial suspensions, and the number of $\mathrm{CFU} / \mathrm{mL}$ was determined for each of the 
contacts after 24,48 , and $72 \mathrm{~h}$. The results of the in vitro antifungal assays demonstrated that all the CS-HAp coatings exhibited a strong inhibitory effect against the development of the tested microbial cells, even after $24 \mathrm{~h}$ of incubation, compared to the positive control $(\mathrm{C}+)$. Moreover, the results depicted in Figure 11 also suggested that the inhibitory effect of the samples increased with the incubation time and that the CS-HAp_3 coatings exhibited the strongest inhibitory effect against $C$. albicans fungal cells for all tested intervals.

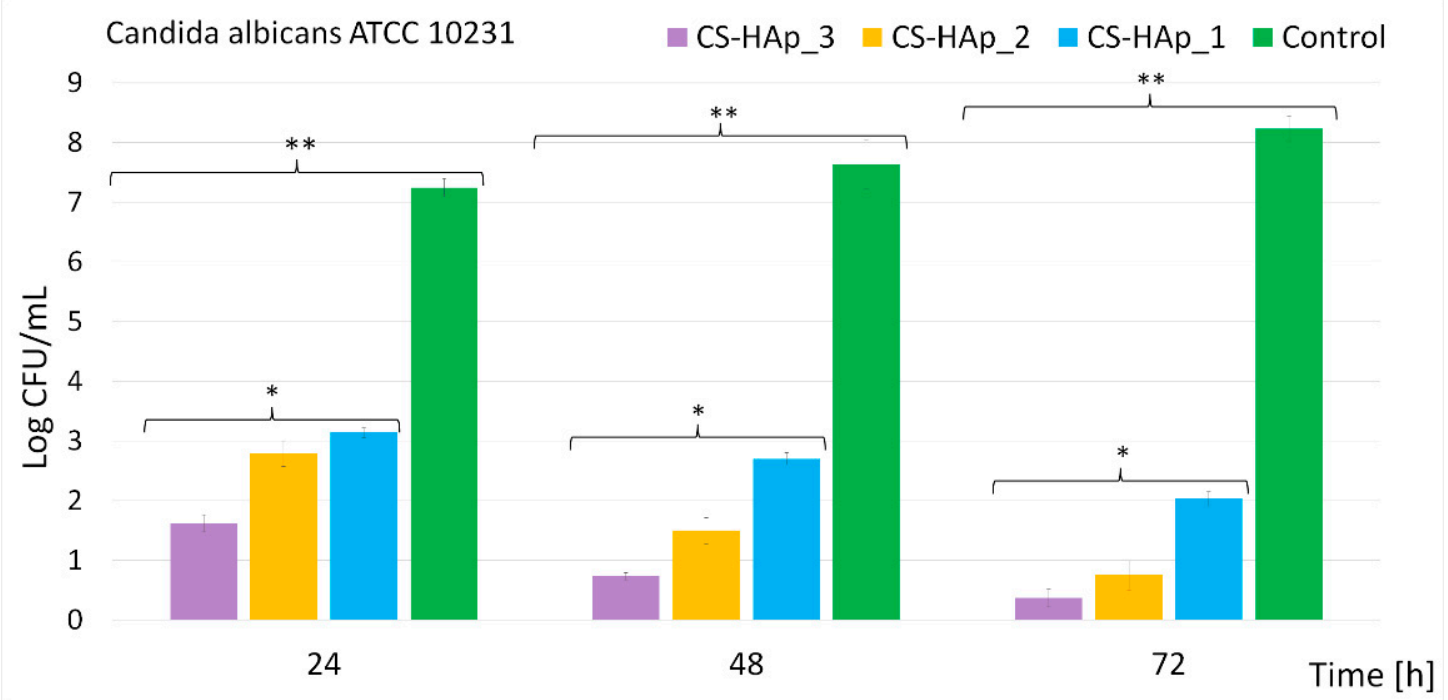

Figure 11. Antimicrobial activity of CS-HAp layers against Candida albicans ATCC 10231 at different time intervals. The results are presented as mean $\pm \mathrm{SD}$. Statistical analysis was performed by one-way ANOVA. The $p$-values indicated are the following: ${ }^{*} p \leq 0.003,{ }^{* *} p \leq 0.0001$.

In addition, a viable cell count (VCC) assay was performed to confirm the qualitative and quantitative investigations. The results of the VCC assay depicted in Figure 12 revealed a significant decrease in viable cells after $24 \mathrm{~h}$ of incubation with the CS-HAp composite layers. The number of VCCs was assessed only after $24 \mathrm{~h}$ of incubation, because after 48 and $72 \mathrm{~h}$ no viable cell counts could be recovered from the tested materials. Moreover, the VCC assay confirmed the results of the SEM and CLSM studies, and that emphasized that the layers did not allow $C$. albicans biofilm formation.

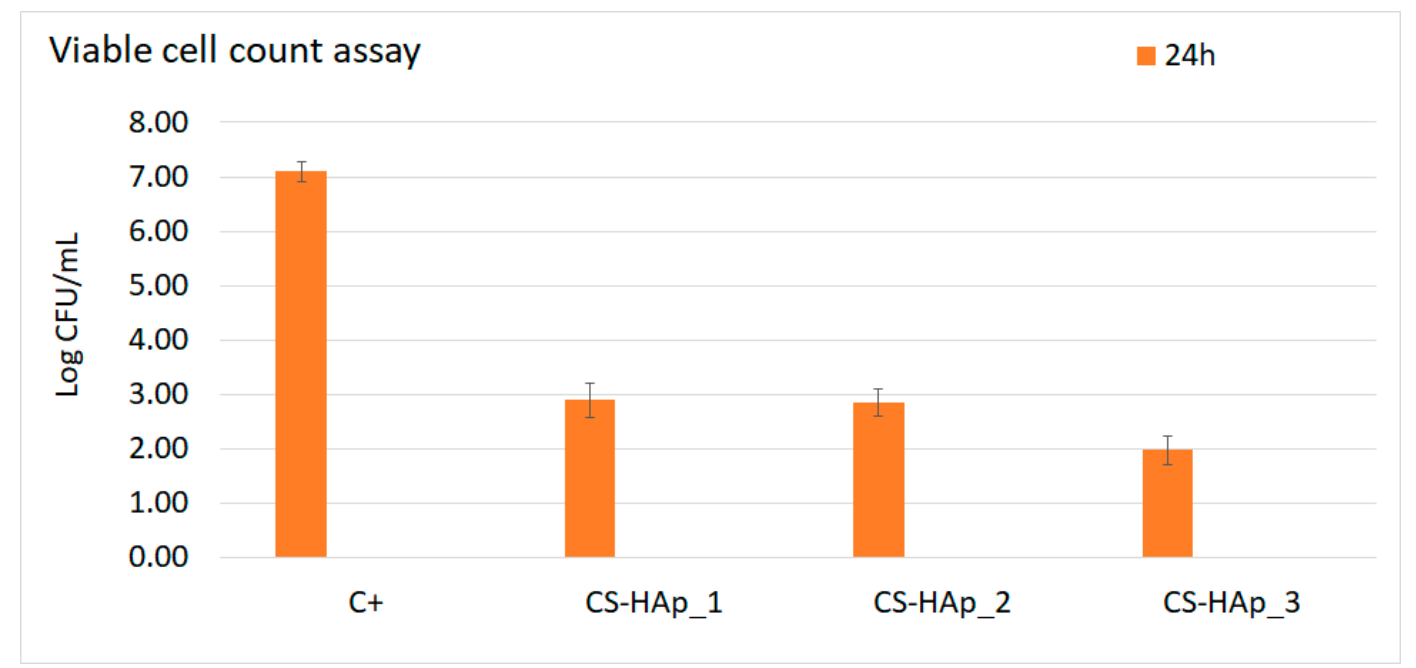

Figure 12. Viable cell count assay of C. albicans fungal strain incubated with CS-HAp composite layers. 
These results are also in good agreement with the qualitative antifungal assays, demonstrating that the CS-HAp_3 coatings presented a stronger inhibitory effect against C. albicans fungal cells. Furthermore, the SEM visualization has shown that the CS-HAp coatings obtained at various Ar gas working pressures $\left(p=2 \times 10^{-3}\right.$ mbarr; $p=5 \times 10^{-3}$ mbarr; $p=1.2 \times 10^{-2}$ mbarr) have successfully inhibited $C$. albicans cell proliferation, even after $24 \mathrm{~h}$ of incubation. Moreover, the SEM and CLSM images emphasized that on the surface of the coatings exposed to C. albicans microbial suspensions the remaining adhered microbial cells were isolated. In addition, both SEM and CLSM studies revealed that there was no indication of hyphal formation, which is a proof of inhibition of the first steps in biofilm formation. These results are in good agreement with previous reported studies regarding the antimicrobial properties of chitosan and chitosan/hydroxyapatite compounds $[8,9,11,12,37-44]$. Even though there have been many proposals of antimicrobial mechanisms in the literature, their understanding is still scarce. In terms of chitosan antimicrobial activity, several mechanisms of interaction between chitosan and microbial cells have been proposed. Firstly, one of the most well-known and accepted mechanisms is one based on the interaction between the positive charge surface of the studied materials and anionic components from the microbial strain structure (such as lipopolysaccharides and proteins), which leads to disruption and subsequent death of microbial cells $[45,46]$. Secondly, another proposed mechanism is based on the interaction between cytoplasmic membrane and chitosan, the latter modifying cell permeability and thus altering the transport of nutrients in the microbial cell, which finally leads to cell death due to lack of essential nutrients for the cell $[45,46]$. Another mechanism, less common, proposes intracellular targets of chitosan after penetrating the microbial cell wall and cytoplasmic membrane. This mechanism is based on the chitosan interaction with DNA, which ultimately leads to cell death due to the prevention of DNA replication and transcription [46]. Finally, another mechanism proposed in few studies is based on the chelating properties of metal ions by chitosan [46]. In addition, the antimicrobial properties of materials are also correlated with numerous factors, such as the type of microbial cell, the type of antimicrobial agent (powders, dispersion, nanoparticles, coatings, etc.), and other parameters that could influence the interaction between the microbial cell and the studied material, such as ambient temperature, $\mathrm{pH}$ value, etc. In addition, a considerable factor in antimicrobial properties, in the case of coatings, is the synergistic interactions that appear between the substrate and the coating, which could improve or generate new properties of the materials and/or substrate [47]. In our study, since hydroxyapatite was reported not to exhibit antifungal activity, the antifungal activity presented by the CS-HAp composite layers could be attributed to the chitosan or to the synergistic interaction that took place between the substrate and coating material. Nonetheless, these preliminary findings could lead to the premise that the CS-HAp coatings obtained at various Ar gas working pressures $\left(p=2 \times 10^{-3}\right.$ mbarr; $p=5 \times 10^{-3}$ mbarr; $p=1.2 \times 10^{-2}$ mbarr $)$ might be suitable for the development of novel antimicrobial agents.

\section{Conclusions}

CS-HAp composite layers deposited on Si substrates were developed in radio frequency (RF) magnetron sputtering discharge in argon gas. The important infrared bands allowed us to highlight the presence of CS and HAp in the deposited layers. Moreover, the analysis of CS-HAp layers was performed using second-order derivative spectra. Investigation of CS-HAp layers by SEM, MM, and AFM showed that they have a homogeneous surface. No cracks or discontinuities were observed on the surface of the coatings. SEM, $\mathrm{MM}$, and AFM investigations have shown that the surface of CS-HAp composite layers is influenced by argon (Ar) gas working pressure. If at the lowest pressure $\left(2 \times 10^{-3} \mathrm{mbar}\right) \mathrm{a}$ uniform increase was observed, at the highest pressure $\left(1.2 \times 10^{-2} \mathrm{mbar}\right)$ a granular surface was observed, while at the pressure of $\left(5 \times 10^{-3} \mathrm{mbar}\right)$ the surface was well structured. The antifungal assay emphasized that the CS-HAp composite layers inhibited C. albicans biofilm formation and also had a goof inhibitory effect against the development of $C$. 
albicans fungal cells. Therefore, due to their unique physicochemical properties highlighted in our paper, the hydroxyapatite-chitosan composite coatings could be a suitable candidate for biomedical applications.

Author Contributions: Conceptualization, M.B., C.S.C. and D.P.; methodology, M.B., C.S.C., and D.P.; software, S.L.I. and C.S.C.; validation, M.B., C.S.C., S.L.I. and D.P.; formal analysis, M.B., C.S.C., S.L.I., D.P., A.M.P. and A.G.; investigation, A.M.P., R.-D.T., M.C.C. and A.G.; resources, M.B. and D.P.; data curation, M.B., C.S.C., D.P., and S.L.I.; writing-original draft preparation, M.B., C.S.C., S.L.I., D.P. and A.G.; writing-review and editing, M.B., C.S.C., S.L.I. and D.P.; visualization, M.B., C.S.C., S.L.I., D.P., R.-D.T., A.M.P., M.C.C. and A.G.; supervision, M.B., C.S.C. and D.P.; project administration, M.B. and C.S.C.; funding acquisition, M.B. and D.P. All authors have read and agreed to the published version of the manuscript.

Funding: This research was funded by the Romanian Ministry of Research and Innovation with the grant number PN-III-P1-1.2-PCCDI-2017-0629/contract No. 43PCCDI/2018 and grant number PN-III-P2-2.1-PED2019-0868/contract No. 467PED/2020, and the APC was funded by the Romanian Ministry of Research and Innovation project number PN-III-P1-1.2-PCCDI-2017-0629/contract No. 43PCCDI/2018 and grant number PN-III-P2-2.1-PED-2019-1375/contract No. 331PED/2020".

Institutional Review Board Statement: Not applicable.

Informed Consent Statement: Not applicable.

Data Availability Statement: Data is contained within the article.

Conflicts of Interest: The authors declare no conflict of interest.

\section{References}

1. Surmenev, R.; Vladescu, A.; Surmeneva, M.; Ivanova, A.; Braic, M.; Grubova, I.; Cotrut, C.M. Radio Frequency Magnetron Sputter Deposition as a Tool for Surface Modification of Medical Implants Chapter 12. In Modern Technologies for Creating the Thin-film Systems and Coatings; Nikitenkov, N.N., Ed.; IntechOpen: London, UK, 2017; pp. 213-248. [CrossRef]

2. Teh, S.J.; Lai, C.W. Carbon Nanotubes for Dental Implants. In Applications of Nanocomposite Materials in Dentistry; Asiri, A.M., Mohammad, A.I., Eds.; Woodhead Publishing Series in Biomaterials; Woodhead Publishing: Cambridge, UK, 2019 ; pp. 93-105. [CrossRef]

3. Surmenev, R.A.; Surmeneva, M.A.; Grubova, I.Y.; Chernozem, R.V.; Krause, B.; Baumbach, T.; Loza, K.; Epple, M. RF magnetron sputtering of a hydroxyapatite target: A comparison study on polytetrafluorethylene and titanium substrates. Appl. Surf. Sci. 2017, 414, 335-344. [CrossRef]

4. Liu, X.; Wu, Y.; Zhao, X.; Wang, Z. Fabrication and applications of bioactive chitosan-based organic-inorganic hybrid materials: A review. Carbohydr. Polym. 2021, 267, 118179. [CrossRef] [PubMed]

5. Atak, B.H.; Buyuk, B.; Huysal, M.; Isik, S.; Senel, M.; Metzger, W.; Cetin, G. Preparation and characterization of amine functional nano-hydroxyapatite/chitosan bionanocomposite for bone tissue engineering applications. Carbohydr. Polym. 2017, 164, 200-213. [CrossRef] [PubMed]

6. Sánchez, A.; Prokhorov, E.; Luna-Bárcenas, G.; Mora-García, A.G.; Kovalenko, Y.; Rivera-Muñoz, E.; Raucci, M.; Buonocore, G. Chitosan-hydroxyapatite nanocomposites: Effect of interfacial layer on mechanical and dielectric properties. Mater. Chem. Phys. 2018, 217, 151-159. [CrossRef]

7. Jabłońska, J.; Onyszko, M.; Konopacki, M.; Augustyniak, A.; Rakoczy, R.; Mijowska, E. Fabrication of paper sheets coatings based on chitosan/bacterial nanocellulose/ZnO with enhanced antibacterial and mechanical properties. Int. J. Mol. Sci. 2021, 22, 7383. [CrossRef]

8. Ke, C.-L.; Deng, F.-S.; Chuang, C.-Y.; Lin, C.-H. Antimicrobial actions and applications of chitosan. Polymers 2021, $13,904$. [CrossRef]

9. Li, B.; Xia, X.; Guo, M.; Jiang, Y.; Li, Y.; Zhang, Z.; Liu, S.; Li, H.; Liang, C.; Wang, H. Biological and antibacterial properties of the micronanostructured hydroxyapatite/chitosan coating on titanium. Sci. Rep. 2019, 9, 14052. [CrossRef]

10. Liao, Y.; Li, H.; Shu, R.; Chen, H.; Zhao, L.; Song, Z.; Zhou, W. Mesoporous hydroxyapatite/chitosan loaded with recombinanthuman amelogenin could enhance antibacterial effect and promote periodontal regeneration. Front. Cell Infect. Microbiol. 2020, 10, 180. [CrossRef]

11. Nicol, M.J.; Brubaker, T.R.; Honish, B.J.; Simmons, A.N.; Kazemi, A.; Geissel, M.A.; Whalen, C.T.; Siedlecki, C.A.; Bilén, S.G.; Knecht, S.D.; et al. Antibacterial effects of low-temperature plasma generated by atmospheric-pressure plasma jet are mediated by reactive oxygen species. Sci. Rep. 2020, 10, 3066. [CrossRef]

12. Barjasteh, A.; Dehghani, Z.; Lamichhane, P.; Kaushik, N.; Choi, E.H.; Kaushik, N.K. Recent progress in applications of non-thermal plasma for water purification, bio-sterilization, and decontamination. Appl. Sci. 2021, 11, 3372. [CrossRef] 
13. Cheng, J.H.; Lv, X.; Pan, Y.; Sun, D.W. Foodborne bacterial stress responses to exogenous reactive oxygen species (ROS) induced by cold plasma treatments. Trends Food Sci. Technol. 2020, 103, 239-247. [CrossRef]

14. Castro-Alférez, M.; Polo-López, M.I.; Fernández-Ibáñez, P. Intracellular mechanisms of solar water disinfection. Sci. Rep. 2016, 6, 38145. [CrossRef]

15. Kaushik, N.K.; Bekeschus, S.; Tanaka, H.; Lin, A.; Choi, E.H. Plasma medicine technologies. Appl. Sci. 2021, 11, 4584. [CrossRef]

16. Yost, A.D.; Joshi, S.G. Atmospheric nonthermal plasma-treated PBS inactivates Escherichia coli by oxidative DNA damage. PLoS ONE 2015, 10, e0139903. [CrossRef] [PubMed]

17. Pighinelli, L.; Kucharska, M. Chitosan-hydroxyapatite composites. Carbohydr. Polym. 2013, 93, 256-262. [CrossRef]

18. Gritsch, L.; Maqbool, M.; Mouriño, V.; Ciraldo, F.E.; Cresswell, M.; Jackson, P.R.; Lovell, C.; Boccaccini, A.R. Chitosan/hydroxyapatite composite bone tissue engineering scaffolds with dual and decoupled therapeutic ion delivery: Copper and strontium. J. Mater. Chem. B 2019, 7, 6109-6124. [CrossRef] [PubMed]

19. Pistone, A.; Iannazzo, D.; Celesti, C.; Piperopoulos, E.; Ashok, D.; Cembran, A.; Tricoli, A.; Nisbet, D. Engineering of chitosanhydroxyapatite-magnetite hierarchical scaffolds for guided bone growth. Materials 2019, 12, 2321. [CrossRef] [PubMed]

20. Boudemagh, D.; Venturini, P.; Fleutot, S.; Cleymand, F. Elaboration of hydroxyapatite nanoparticles and chitosan/hydroxyapatite composites: A present status. Polym. Bull. 2019, 76, 2621-2653. [CrossRef]

21. Jia, L.; Liang, C.; Huang, N.; Zhou, Z.; Duan, F.; Wang, L. Morphology and composition of coatings based on hydroxyapatitechitosan-RuCl3 system on AZ91D prepared by pulsed electrochemical deposition. J. Alloys Compd. 2016, 656, 961-971. [CrossRef]

22. Sutha, S.; Kavitha, K.; Karunakaran, G.; Rajendran, V. In-vitro bioactivity, biocorrosion and antibacterial activity of silicon integrated hydroxyapatite/chitosan composite coating on 316 L stainless steel implants. Mater. Sci. Eng. C 2013, 33, 4046-4054. [CrossRef]

23. Song, L.; Gan, L.; Xiao, Y.F.; Wu, Y.; Wu, F.; Gu, Z.W. Antibacterial hydroxyapatite/chitosan complex coatings with superior osteoblastic cell response. Mater. Lett. 2011, 65, 974-977. [CrossRef]

24. Dreghici, D.B.; Butoi, B.; Predoi, D.; Iconaru, S.L.; Stoican, O.; Groza, A. Chitosan-hydroxyapatite composite layers generated in radio frequency magnetron sputtering discharge: From plasma to structural and morphological analysis of layers. Polymers 2020, 12, 3065. [CrossRef]

25. Groza, A.; Dreghici, D.B.; Ganciu, M. Calcium phosphate layers deposited on thermal sensitive polymer substrates in radio frequency magnetron plasma discharge. Coatings 2019, 9, 709. [CrossRef]

26. Choukourov, A.; Pleskunov, P.; Nikitin, D.; Titov, V.; Shelemin, A.; Vaidulych, M.; Kuzminova, A.; Solař, P.; Hanuš, J.; Kousal, J.; et al. Advances and challenges in the field of plasma polymer nanoparticles. Beilstein J. Nanotechnol. 2017, 8, 2002-2014. [CrossRef]

27. Friedrich, J. Mechanisms of plasma polymerization-Reviewed from a chemical point of view. Plasma Process. Polym. 2011, 8 , 783-802. [CrossRef]

28. Cobos, M.; De-La-Pinta, I.; Quindos, G.; Fernandez, M.J.; Fernandez, M.D. Graphene oxide-silver nanoparticle nanohybrids: Synthesis, characterization, and antimicrobial properties. Nanomaterials 2020, 10, 376. [CrossRef]

29. Iconaru, S.L.; Prodan, A.M.; Buton, N.; Predoi, D. Structural characterization and antifungal studies of zinc-doped hydroxyapatite coatings. Molecules 2017, 22, 604. [CrossRef]

30. Cuero, R.G. Antimicrobial action of exogenous chitosan. EXS 1999, 87, 315-333. [CrossRef]

31. Predoi, D.; Iconaru, S.L.; Predoi, M.V.; Groza, A.; Gaiaschi, S.; Rokosz, K.; Raaen, S.; Negrila, C.C.; Prodan, A.-M.; Costescu, A.; et al. Development of cerium-doped hydroxyapatite coatings with antimicrobial properties for biomedical applications. Coatings 2020, 10, 516. [CrossRef]

32. Iconaru, S.L.; Motelica-Heino, M.; Predoi, D. Study on europium-doped hydroxyapatite nanoparticles by fourier transform infrared spectroscopy and their antimicrobial properties. J. Spectrosc. 2013, 2013, 284285. [CrossRef]

33. ImageJ. Available online: http:/ /imagej.nih.gov/ij (accessed on 10 January 2021).

34. Gwyddion. Available online: http://gwyddion.net/ (accessed on 20 January 2021).

35. Chen, F.; Wang, Z.; Lin, C. Preparation and characterization of nano-sized hydroxyapatite particles and hydroxyapatite/chitosan nano-composite for use in biomedical materials. Mater. Lett. 2002, 57, 858-861. [CrossRef]

36. Predoi, D.; Iconaru, S.L.; Predoi, M.V. Fabrication of Silver-and zinc-doped hydroxyapatite coatings for enhancing antimicrobial effect. Coatings 2020, 10, 905. [CrossRef]

37. Cunha, C.S.; Castro, P.J.; Sousa, S.C.; Pullar, R.C.; Tobaldi, D.M.; Piccirillo, C.; Pintado, M.M. Films of chitosan and natural modified hydroxyapatite as effective UV-protecting, biocompatible and antibacterial wound dressings. Int. J. Biol. Macromol. 2020, 159, 1177-1185. [CrossRef] [PubMed]

38. Huang, D.; Zuo, Y.; Zou, Q.; Zhang, L.; Li, J.; Cheng, L.; Shen, J.; Li, Y. Antibacterial chitosan coating on nanohydroxyapatite/polyamide66 porous bone scaffold for drug delivery. J. Biomater. Sci. Polym. Ed. 2011, 22, 931-944. [CrossRef] [PubMed]

39. Rabea, E.I.; Badawy, M.E.; Stevens, C.V.; Smagghe, G.; Steurbaut, W. Chitosan as antimicrobial agent: Applications and mode of action. Biomacromolecules 2003, 4, 1457-1465. [CrossRef]

40. Fakhri, E.; Eslami, H.; Maroufi, P.; Pakdel, F.; Taghizadeh, S.; Ganbarov, K.; Yousefi, M.; Tanomand, A.; Yousefi, B.; Mahmoudi, S.; et al. Chitosan biomaterials application in dentistry. Int. J. Biol. Macromol. 2020, 162, 956-974. [CrossRef] 
41. Morsy, R.; Ali, S.S.; El-Shetehy, M. Development of hydroxyapatite-chitosan gel sunscreen combating clinical multidrug-resistant bacteria. J. Mol. Struct. 2017, 1143, 251-258. [CrossRef]

42. Kumar, S.; Mukherjee, A.; Dutta, J. Chitosan based nanocomposite films and coatings: Emerging antimicrobial food packaging alternatives. Trends Food Sci. Technol. 2020, 97, 196-209. [CrossRef]

43. Costa-Pinto, A.R.; Lemos, A.L.; Tavaria, F.K.; Pintado, M. Chitosan and hydroxyapatite based biomaterials to circumvent periprosthetic joint infections. Materials 2021, 14, 804. [CrossRef]

44. Kumar, S.; Isloor, A.M.; Kumar, G.M.; Asiri, A.M. Nanohydroxyapatite reinforced chitosan composite hydrogel with tunable mechanical and biological properties for cartilage regeneration. Sci. Rep. 2019, 9, 15957. [CrossRef]

45. Helander, I.M.; Nurmiaho-Lassila, E.L.; Ahvenainen, R.; Rhoades, J.; Roller, S. Chitosan disrupts the barrier properties of the outer membrane of gram-negative bacteria. Int. J. Food Microbiol. 2001, 71, 235-244. [CrossRef]

46. Sahariah, P.; Masson, M. Antimicrobial chitosan and chitosan derivatives: A review of the structure-activity relationship. Biomacromolecules 2017, 18, 3846-3868. [CrossRef] [PubMed]

47. Tuson, H.H.; Weibel, D.B. Bacteria-Surface interactions. Soft Matter 2013, 9, 4368-4380. [CrossRef] [PubMed] 